\title{
AGRESSIVIDADE E INTELIGÊNCIA NA ADOLESCÊNCIA
}

\author{
Juliana Munique de Souza Siqueira \\ Psicóloga graduada na Universidade São Francisco.
}

Claudette Maria Medeiros Vendramini

Estatística. Doutora em Educação pela Universidade Estadual de Campinas. É professora associada doutora da graduação e Pós-Graduação em Psicologia da Universidade São Francisco.

\begin{abstract}
Resumo
Este estudo objetivou analisar a agressividade e a inteligência na adolescência e verificar se existe associação entre essas variáveis. A agressividade é inerente à natureza humana e colabora no processo de construção da personalidade influenciando os comportamentos de forma positiva ou negativa. A inteligência se refere à habilidade cognitiva que cada indivíduo possui e contribui para o estabelecimento de relações sociais. Na adolescência tanto a agressividade quanto a inteligência se tornam mais evidentes devido às transformações desta fase do desenvolvimento. Participaram desta pesquisa 35 adolescentes de ambos os sexos. Os instrumentos utilizados foram a Bateria de Provas de Raciocínio BPR-5 e a Escala de Agressividade para Crianças e Jovens. Os resultados indicaram que não existe relação entre agressividade e inteligência. No entanto, com base na literatura essas variáveis se inter-relacionam. Sendo assim, sugere-se que esta pesquisa seja ampliada com a utilização de outros instrumentos psicológicos.
\end{abstract}

Palavras-chave: adolescente; desenvolvimento cognitivo; interação social.

\section{AGGRESSIVENESS AND INTELLIGENCE IN ADOLESCENCE}

\begin{abstract}
This study aimed to analyse the aggressiveness and intelligence in adolescence, and to verify if exists association through these variables. The aggressiveness is inherent in human nature and collaborates in the construction of personality by influencing the behaviors positively or negatively. Intelligence refers to the cognitive skill that every individual has and contributes to the establishment of social relations. As a teenager the aggressiveness and the intelligence become more evident due to change in this phase of development. The sample of 35 adolescents of both sexes participated in this survey. The instruments used were the batch of reasoning tests - BPR-5 and the Aggressiveness scale for children and young people. The results indicated that there is no relationship between aggression and intelligence. However, based on the literature these variables interrelate. Therefore, it is suggested that this research be expanded with the use of other psychological instruments.
\end{abstract}

Keywords: adolescence; cognitive development; social interaction. 


\title{
AGRESIVIDAD Y INTELIGENCIA EN LA ADOLESCENCIA
}

\begin{abstract}
Resumen
Este estudio pretende analizar la inteligencia y la agresividad en la adolescencia y compruebe que hay una asociación entre estas variables. La agresividad es inherente a la naturaleza humana y colabora en la construcción de la personalidad, influyendo en las conductas positivamente o negativamente. Inteligencia se refiere a la habilidad cognitiva que cada individuo posee y contribuye al establecimiento de las relaciones sociales. Como un adolescente la agresividad and la inteligencia se hacen más evidentes debido a cambiar en esta fase de desarrollo. Una amuestra de 35 adolescentes de ambos sexos participaron en esta pesquisa. Los instrumentos utilizados fueron lo conjunto de testes de raciocinio - BPR-5 y la Escala de agresividad para niños y jóvenes. Los resultados indicaron que no existe relación entre la agresión y la inteligencia. Sin embargo, con base en la literatura estas variables se interrelacionan. Por lo tanto, se sugiere que esta investigación se amplíe con el uso de otros instrumentos psicológicos.
\end{abstract}

Palabras clave: adolescente; desarrollo cognitivo; interacción social.

\section{INTRODUÇÃO}

A agressividade, de acordo com Hall, Lindzey e Campbell (2000), é definida como aquilo que dá ordem ou congruência a todos os comportamentos apresentados pelo indivíduo, ou seja, consiste nos esforços de ajustamentos variados e, portanto, típicos do indivíduo. Segundo Winnicott (2000), a agressividade faz parte do processo de desenvolvimento antes do nascimento e permanece presente no decorrer do desenvolvimento do indivíduo colaborando para integração da personalidade. Como apresentado por Keppe (2005), a agressividade se apresenta em três estágios: $01^{0}$ estágio de pré-integração, de propósito sem piedade, é aquele no qual não se tem uma preocupação em relação aos outros, considerando que esta fase é a de satisfação de necessidades do indivíduo; o $2^{\circ}$ estágio de integração, de propósito com piedade e culpa, é aquele que resulta no sentimento de culpa pelo ato agressivo, em uma relação de amor e ódio; e, o $3^{\circ}$ estágio de relações interpessoais, situações triangulares e conflitos, conscientes e inconscientes, é o que se refere ao controle da agressividade madura observada em adolescentes, que motiva a competição em jogos e no trabalho.

O comportamento agressivo, ou melhor, a hostilidade primária dos seres humanos ameaça a vida em sociedade e leva a mesma à desintegração. No entanto, segundo Freud (1930), o comportamento agressivo é entendido como resultado de um processo defensivo na sociedade. Mediante este tipo de comportamento a sociedade utiliza mecanismos diversos para "estabelecer limites para os instintos agressivos do homem e manter suas manifestações sob 
controle por formações psíquicas reativas" (p.117), e manter a ordem social através de leis de convívio. Muitos adolescentes e, em geral, a sociedade, podem negar a existência da agressividade em si, porém esta pode ser apresentada através de atos ou somente reconhecida por si através do pensamento, mas não deixa de existir. Para Freud (1930),

\begin{abstract}
a agressividade é introjetada, internalizada; ela é na realidade, enviada de volta para o lugar de onde proveio, isto é, dirigida no sentido do seu próprio ego. Aí, é assumida por uma parte do ego, que se coloca contra o resto do ego, como superego, e que então, sob a forma de consciência, está pronta para pôr em ação contra o ego a mesma agressividade rude que o ego teria gostado de satisfazer sobre outros indivíduos, a ele estranhos. (p.127)
\end{abstract}

No livro Privação e Delinquência, no texto Agressão e suas raízes, Winnicott (1987) concorda com Freud que a agressividade faz parte do ser humano e expõe que o amor e ódio são elementos de referência que possibilita a construção das relações humanas. Desta forma, amor e ódio envolvem agressividade. No entanto, a agressividade, segundo o autor, é uma tendência humana que sempre é desviada e é atribuída a agentes externos quando ocorre sua manifestação. Por isso, é difícil identificar qual a origem da mesma. Comumente o homem não admite a existência da agressividade em si, porém a mesma pode ser apresentada de forma explícita ou implícita. Na civilização o comportamento é regido por leis que submetem a sociedade a restrições, caso não as cumpre está sujeito a punições.

Assim, o comportamento antissocial não está relacionado a transtornos psiquiátricos, pode ser encontrado em indivíduos de qualquer faixa etária, que quando crianças tiveram privação emocional, ou seja, faltaram cuidados essenciais para seu desenvolvimento. Cada indivíduo possui uma capacidade diferenciada para lidar com o ambiente, que influenciará na forma que a agressividade se manifestará. O comportamento agressivo representa a ausência de algo que é importante para o ser humano e que teve restrição (Winnicott, 1987).

No caso do adolescente, que para adaptar-se ao ambiente trava uma luta para sentir-se real já possuindo um controle da agressividade maduro, esse enfrenta situações diferentes de quando era criança, pelo fato que sua capacidade de destruir é tamanha e efetiva, e o mesmo terá que arcar com a responsabilidade perante suas ações (Dias, 2000). Portanto, o comportamento agressivo influencia no desenvolvimento pessoal e na vida em grupo, ou melhor, 
na sociedade. Se comportar de forma agressiva revela as dificuldades de interação e adaptação, especialmente entre crianças e adolescentes, dentro do contexto social em que estão inseridos (Joly, Dias, \& Marini, 2009).

Diversos autores já se debruçaram em pesquisas sobre a agressividade, entre eles Bierman, Smoot e Aumiller (1993), que realizaram uma pesquisa com a participação de 95 pessoas do sexo masculino, com idades de 6 a 12 anos de idade. Os participantes foram selecionados com base nas medidas sociométricas e na avaliação da agressividade, que foi realizada por meio de observações do comportamento dos alunos, avaliação dos professores e dos colegas. Também foram utilizadas entrevistas para verificar como os comportamentos agressivos eram classificados. Desta forma, foram organizados quatro subgrupos, sendo eles: agressivo e rejeitado, agressivo e não rejeitado, rejeitado e não agressivo e não agressivo e não rejeitado. Os resultados demonstraram que os garotos agressivos e rejeitados apresentaram maior nível de conduta severa (mais agressivos no relacionamento interpessoal) do que os garotos classificados como agressivos e não rejeitados. Já o grupo classificado como nem agressivos e nem rejeitados, na visão dos professores e dos companheiros de turma, eram vistos como não tendo comportamentos pró-sociais.

Em uma pesquisa realizada por Joly e cols. (2009), foi aplicada a Escala de agressividade em crianças e jovens em uma amostra de 758 crianças da $2^{a}$, $3^{a}$ e $4^{a}$ séries de ambos os sexos. A pesquisa teve como objetivo identificar a percepção de estudantes do ensino fundamental sobre a agressividade na família e na escola, com intuito de verificar possíveis relações entre sexo, idade e série frequentada. Os resultados demonstraram, de forma geral, pouca conduta agressiva. Foi identificada uma influência de gênero sobre a agressividade geral dos participantes, sendo que os meninos apresentaram maior nível de agressividade em relação às meninas. No que se refere à agressividade em família, os participantes demonstraram pouca conduta agressiva. Desta forma, pode-se comprovar que a família tem um papel determinante no comportamento dos filhos. A agressividade familiar em relação à série e ao tipo de escola apresentou aumento nos escores médios de agressividade de acordo com o avanço da série. No contexto escolar, as crianças também demonstraram pouca conduta agressiva, e não foram encontradas diferenças significativas nos resultados quanto à idade e série. 
Outro estudo que se refere à agressividade no contexto escolar foi desenvolvido por Fante (2005, citado por Pródocimo \& Recco, 2008) em que o autor conclui ser a escola o local onde ocorrem inúmeras manifestações de agressividade, principalmente na hora do recreio por ser o momento em que os alunos estão sem a presença do professor. O autor também conclui que os comportamentos agressivos apresentados na escola são decorrentes de uma repetição dos padrões de comportamento das relações familiares e que o ambiente escolar, a mídia, a televisão e o videogame também podem influenciar na conduta agressiva.

Um estudo, realizado por Sisto (2005), teve como foco comparar quatro escolas, sendo que três delas eram estaduais e uma particular. Participaram do estudo 1281 estudantes que forneceram informações que se refere à agressividade e à aceitação-rejeição dos alunos da $2^{a}, 3^{a}$ e $4^{a}$ séries do ensino fundamental. O instrumento utilizado foi a Escala de Agressividade para crianças e jovens e medida sociométrica, que teve como objetivo detectar em que extensão uma criança é escolhida ou rejeitada para a realização de uma atividade por seus colegas. Sendo assim, os alunos indicaram por ordem de preferência aqueles que gostariam ou não de realizar atividades juntos. A escola que apresentou maior pontuação da sociometria está localizada num bairro de periferia, já a escola que apresentou menor pontuação está localizada em um bairro antigo de classe média baixa. A diferença dos resultados entre as escolas foi pequena, a ponto de serem atribuídas ao acaso. Portanto, os resultados sugerem que as relações sociais de aceitação/rejeição se compõem de forma semelhante entre as escolas. Os níveis econômicos e sociais entre as escolas não produziram diferenças significativas. Na visão dos estudantes, foi percebido mais presença de situações que indicam agressividade na situação familiar que na escolar. Já a agressividade em situação escolar e geral tiveram diferenças significativas, pois os alunos da escola particular se perceberam mais agressivos que nas escolas públicas.

No entanto, não é apenas a agressividade que interfere na qualidade das relações sociais, mas também a inteligência, que é um fator importante para a interação dos indivíduos. A inteligência é definida como a capacidade que o ser humano possui para se adaptar ao meio ambiente. Há muito tempo se estuda as habilidades cognitivas humanas, de modo que diversos autores possuem visões diferenciadas sobre a natureza da inteligência, ou seja, das habilidades 
intelectuais. Sendo assim, o desenvolvimento cognitivo se dá através de mudanças qualitativas, que se referem ao pensamento, e também mudanças quantitativas, que se relacionam à capacidade que o indivíduo possui e ao aumento de seu conhecimento. Essas mudanças ocorrem devido à interação da maturação e da aprendizagem, ou seja, das experiências adquiridas na infância e que perduram no decorrer do desenvolvimento (Sternberg, 2000).

No ano de 1921, psicólogos definiram a inteligência como a capacidade que o indivíduo possui para aprender de acordo com suas experiências e capacidade de se adaptar ao ambiente (Sternberg, 2000). Para Dalgalorrondo (2008) podese definir a inteligência como sendo um conjunto de habilidades cognitivas que o indivíduo possui, ou seja, a capacidade que possibilita que o mesmo possa desenvolver habilidades, tais como: raciocínio, planejamento, compreensão de ideias complexas, pensamento abstrato e aprendizagem através de atividades diárias.

Já Pasquali (2003) relata que o grande avanço da avaliação da inteligência foi realizado pelo psicólogo britânico Charles Spearman em 1904, quando demonstrou que seria possível o auxílio da Estatística para compreender os processos cognitivos pela análise fatorial, propondo um fator geral de inteligência (Fator g) para explicar o seu funcionamento. Anastasi e Urbina (2000) relatam que em 1938 Thurstone desenvolveu a Teoria das Aptidões Primárias, contestando a existência de um fator g de Spearman, e propunha a existência de um pequeno número de fatores independentes ou capacidades mentais primárias, tais como: compreensão verbal, fluência verbal, habilidade numérica, raciocínio espacial, memória associativa e velocidade perceptual, e raciocínio indutivo.

Outros pesquisadores também questionaram sobre a existência de uma "inteligência geral", pois acreditavam que os testes de inteligência apresentavam várias capacidades mentais que são relativamente independentes (Atkinson, Atlinson, Smith, Bem, \& Nolem-Hoehsema, 2002). A meta-análise realizada por Carrol teve como resultados um modelo hierárquico da inteligência, que envolve três níveis de processos mentais sendo conhecida como a Teoria dos Três Estratos. Esta estrutura hierárquica possui diversos fatores em diferentes camadas que contribuem para medir as habilidades cognitivas, como descreve Oliveira (2006). 
Essas habilidades também foram estudadas por outros autores e nomeadas como inteligência fluida (Gf) e inteligência cristalizada (Gc). Segundo Primi e Almeida (2000), a inteligência fluida é definida como a capacidade de raciocinar (estabelecer relações e generalizações) referente a problemas novos que ainda não possuem uma solução previamente aprendida. Desta forma, representa a capacidade biológica do sujeito ou do seu potencial intelectual. Sendo assim, a inteligência fluida está associada à capacidade básica de raciocínio aos processos mentais superiores e tem pouca relação com aspectos culturais, ou seja, conhecimentos previamente adquiridos.

Já a inteligência cristalizada, como relatam Primi e Almeida (2000), demonstra a capacidade intelectual do sujeito evoluindo no decorrer do processo de internalização da cultura, utilizando as experiências educativas e culturais, ou seja, utiliza uma determinada quantidade de conhecimento adquirido. Está relacionada com a capacidade de resolução de problemas pela utilização de esquemas aprendidos e armazenados na memória. A inteligência fluida pode ser avaliada por meio de teste de relação semântica, amplitude de memória e indução, enquanto as provas de compreensão verbal ou de cálculo estão relacionadas com a inteligência cristalizada (Primi \& Almeida, 2000).

Além dessas definições da inteligência com base cognitiva, é possível analisar a mesma, vista pela perspectiva genética de Henri Wallon. Este demonstra que a inteligência e a afetividade estão integradas, ou seja, a evolução da afetividade depende de construções e elaborações realizadas no plano da inteligência, da mesma forma a evolução da inteligência depende de construções afetivas (Galvão, 1995). A inteligência é necessária para o processo de sociabilidade do ser humano, ou seja, permite que o mesmo possa estabelecer relações interpessoais. As funções intelectuais permitem a captação de dados externos através da observação, em seguida aciona as funções de elaboração que permite a interpretação dos dados que resulta no processo de pensar ou formular ideias, e por fim as concepções realizadas são expressas por meio da comunicação. Na adolescência, as funções intelectuais tornam-se mais aprimoradas favorecendo ao processo de desenvolvimento individual (Coelho, 1980).

Uma pesquisa realizada por Almeida, Lemos, Guisande e Primi (2008) teve como objetivo verificar em qual medida os resultados de adolescentes em provas de raciocínio se diferenciavam em função de idade e série escolar. Participaram 
1835 alunos divididos de forma balanceada nas 7a, $8^{a}$ e $9^{a}$ série escolar. 0 instrumento utilizado foi a Bateria de Provas de Raciocínio versão BPR-7/9 que inclui cinco provas para avaliar as habilidades de raciocínio. Os resultados apresentaram certo aumento no nível médio de realização cognitiva até os 14 anos. Acima desta idade foi observada uma diminuição do resultado. Houve diferenças significativas entre os alunos de $7^{a}$ para $8^{a}$ série, ou seja, teve um aumento do desempenho nas provas (RA, RN e RV). E da $8^{a}$ para a $9^{a}$ série não teve aumento acentuado dos resultados. Os valores dos resultados sugeriram maior impacto da série de cada aluno em face da idade na diferenciação cognitiva. Os alunos mais velhos demonstraram piores resultados e os mais novos tiveram uma relação positiva do desempenho com a idade.

Os autores Almeida e Primi (2004), com o intuito de explorar capacidades cognitivas de adolescentes no grupo de padronização da BPR-5, realizaram um estudo cujo objetivo foi explorar perfis encontrados e comparar a amostra de padronização de brasileiros e portugueses. Foram analisados escores de 3.039 alunos, dentre estes, 1.444 participantes do Brasil e 1.595 participantes de Portugal da amostra de padronização da Forma B da BPR-5 dos dois países. Na amostra de Portugal, 58,1\% dos participantes eram mulheres com idade entre 12 e 21 anos ( $M=16,7 ; D P=1,23)$, na amostra do Brasil, 53,1\% eram mulheres com idade que teve variação de 14 a 53 anos $(M=19,5 ; D P=6,69)$. Na amostra do Brasil, 307 participantes haviam concluído o Ensino Médio. Todos os participantes tinham idade acima de 18 anos. A observação realizada se refere à configuração de perfis, pois é possível encontrar 243 configurações com este instrumento, sendo no Brasil encontrado $189(77,7 \%)$ e em Portugal 208 $(85,6 \%)$, sendo que $174(71,6 \%)$ perfis aparecem nos dois países. Foi observado 224 perfis, dos 243 possíveis. Nesta pesquisa os resultados indicaram uma grande variabilidade dos perfis, sendo estes resumidos e classificados em oito grupos. Os resultados dessa pesquisa sugerem que a BPR-5 demonstra potencial para caracterizar perfis de habilidades dos participantes, pois teve grande variação dos perfis entre sujeitos brasileiros e portugueses.

Mediante os fatores citados como elementos importantes para 0 desenvolvimento na adolescência, outro fator importante já mencionado é a inserção no ambiente escolar, pois a escola é uma experiência organizadora que possibilita a convivência interpessoal e o aprendizado. 0 ambiente escolar oferece oportunidades para adquirir novas habilidades e aperfeiçoá-las, ter 
conhecimento sobre opções vocacionais, formar amigos e participar de atividades físicas. Os adolescentes encontram apoio emocional entre amigos por estarem passando por transformações semelhantes. Sendo assim, o grupo torna-se fonte de afeto, compreensão e segurança para realizar experimentações e conquistar autonomia e independência (Papalia \& Olds, 2000).

Ao mesmo tempo em que procura ser independente, o adolescente ainda é dependente de alguma forma de seus pais. Sendo assim, a hostilidade que o adolescente demonstra em relação aos pais e a sociedade é uma espécie de desconfiança por pensar no fato de não ser compreendido (Aberastury, 1986). Por essas dificuldades, o adolescente tende a se unir a grupos da mesma faixa etária que tenham valores diferenciados dos seus pais para que possam ter a possibilidade de obter novas experiências. Sendo assim, nesta fase o grupo facilita o processo de identificações e permiti compartilhar experiências e segredos que são necessários para o desenvolvimento da personalidade (Erickson, 1998).

O adolescente luta para adquirir sua identidade e percorre caminhos alternativos que podem ser perigosos como, por exemplo, a utilização de entorpecentes e a liberdade sexual como forma de protesto (Aberastury, 1986). Para Winnicott (1975), a adolescência é a fase de construção da identidade, onde se tem como objetivo descobrir o próprio eu. O ser e o fazer ocorrem em função do espaço cultural, do grupo em que está inserido e o compartilhar de ideias e experiências. Desta forma, o ambiente tem uma importante função na constituição do adolescente, pois as diversas dificuldades que o adolescente enfrenta surgem pelas más condições ambientais. Winnicott compreende o adolescente como um ser isolado, apesar dos relacionamentos interpessoais (Oliveira, 2009).

Após expor teorias e estudos referentes à agressividade e a inteligência no período da adolescência, este estudo objetivou analisar a agressividade e a inteligência na adolescência e verificar se existe associação entre essas variáveis.

\section{MÉTODO}

\section{Participantes}

O estudo foi desenvolvido em uma escola estadual situada no interior do Estado de São Paulo. Participaram 35 alunos da $7^{a}$ e $8^{a}$ séries do ensino 
fundamental $(25,7 \%$ e $25,7 \%)$ e do $1^{\circ}$ e 20 ano do ensino médio $(20,0 \%$ e $28,6 \%$ ) respectivamente, com idades entre 13 e 17 anos, média de 14,71 e desvio padrão de 1,30 . Os alunos eram de ambos os sexos, sendo $80,0 \%$ do sexo feminino e $20,0 \%$ do sexo masculino. Entre os participantes $11,4 \%$ trabalham e $88,6 \%$ não trabalham.

\section{Instrumentos}

Utilizou-se nesta pesquisa a Bateria de Provas de Raciocínio (BPR-5) de Primi e Almeida (2000) e a Escala de Agressividade de Sisto e Bazi (2000). A BPR-5 é uma bateria multidimensional padronizada de avaliação das habilidades cognitivas que oferecem estimativas tanto do funcionamento cognitivo geral quanto das forças e fraquezas, em cinco áreas mais específicas: raciocínio abstrato, verbal, visual-espacial, numérico e mecânico. Este instrumento é composto por cinco subtestes e possui duas formas de aplicação, a Forma A, para alunos da sexta a oitava série do Ensino Fundamental e a Forma $B$, para alunos da primeira a terceira série do Ensino Médio. A Prova de Raciocínio Abstrato (RA) possui conteúdo abstrato que envolve analogia com figuras geométricas, por meio da descoberta da relação existente entre os dois primeiros termos e sua aplicação ao terceiro, para se identificar a quarta figura entre as cinco alternativas existentes. A Prova de Raciocínio Verbal (RV) envolve analogia de palavras, por meio de relações tal como citado na prova anterior. A Prova de Raciocínio Espacial (RE) inclui séries de cubos tridimensionais em movimento, em que os movimentos podem ser constantes e é necessário descobrir o movimento através da análise das diferentes faces de cubos. A Prova de Raciocínio Numérico (RN) contém uma série de números lineares ou alternados, em que são necessários dois números para completar a série. $E$, a Prova de Raciocínio Mecânico (RM) é apresentada através de gravuras que retratam um problema e dispõe de opções de respostas. Todas as provas possui um tempo limite para realização, e também apresentam alternativas de resposta.

A correção da BPR-5 é feita pela soma das respostas certas em cada prova e a transformação do número de acertos para Escore-Padrão Normalizado (EPN) e para percentil. Para a correção foi utilizada a versão eletrônica do instrumento sem a necessidade de realizar correção de forma manual. O valor do percentil indica a porcentagem de pessoas que tiveram nota igual ou menor aquela que esta sendo considerada, portanto pode variar de 1 a 100. Também deve ser 
preenchido o gráfico da curva normal, desenhando um ponto na linha de cada prova que corresponde à nota padronizada obtida. A partir da ligação desses pontos pode-se verificar o perfil de cada participante. O escore geral fornece uma estimativa da capacidade geral de raciocínio analítico para resolver problemas.

A Escala de Agressividade de Sisto e Bazi (2000) é uma escala construída a fim de avaliar crianças e jovens. A escala apresenta evidência de validade de construto, obtida pela análise fatorial, e fornece três tipos de medidas, sendo elas: a agressividade em situação familiar, a agressividade em situação escolar e uma medida de agressividade geral, ou seja, a soma das outras duas subescalas. A terceira medida é possível, pois em sua construção foram isolados por análise de componentes dois principais fatores em que estavam relacionados à situação familiar e a situação escolar. A consistência interna da subescala de agressividade em situação familiar foi comprovada pelo coeficiente Alfa de Cronbach de 0,76 ; a consistência interna da subescala de agressividade em situação escolar pelo valor alfa de 0,77 ; e, para a escala geral pelo valor alfa de 0,80 (Sisto \& Oliveira, 2007).

Segundo Sisto (2005), crianças expostas a interações agressivas com suas mães e entre seus pais tenderão a serem agressivas. Em relação à agressividade na escola e na família, encontrou-se mais presença de situações que indicavam agressividade na situação familiar do que na situação escolar. De acordo com o autor, o comportamento agressivo é desencadeado após um processo de avaliação complexo, no qual interagem as variáveis de ordem pessoais e situacionais, que poderá aumentar ou diminuir o nível de ativação que é necessário para impulsionar o comportamento agressivo. Este instrumento é de auto-relato/auto-percepção que contém 16 afirmativas, sendo que 8 são referentes à situação escolar e outras 8 se referem à situação familiar. Os participantes devem responder sim ( 1 ponto) ou não ( 0 pontos), totalizando de 0 a 8 pontos em cada subescala e de 0 a 16 pontos para expressar a agressividade geral. Para a aplicação, foi distribuído um exemplar deste teste para cada participante contendo as afirmativas e o local onde deveriam assinalar a alternativa que mais se aproximava de comportamento realizado. 0 tempo médio de aplicação varia entre 5 e 10 minutos. 


\section{Procedimentos}

Após a aprovação do projeto pelo Comitê de Ética, foi realizado contato com a direção da instituição para definir as salas para entrega do Termo de Consentimento Livre Esclarecido. Este documento foi enviado aos pais/responsáveis pelos alunos solicitando autorização para participação dos seus filhos na pesquisa. Participaram da pesquisa os alunos que entregaram o termo de consentimento assinado pelos pais ou responsável. A aplicação dos instrumentos foi realizada coletivamente pela pesquisadora, em uma sala de aula com no máximo dez alunos, em horário escolar. Foi apresentado o título da pesquisa e foram esclarecidas as instruções para a aplicação dos instrumentos. Em cada subteste os exemplos foram lidos pela pesquisadora, informando o tempo para que respondessem os instrumentos. O tempo médio de aplicação variou entre $1 \mathrm{~h} 20 \mathrm{~min}$ à $1 \mathrm{~h} 30 \mathrm{~min}$.

\section{RESULTADOS E DISCUSSÃO}

Com a finalidade de descrever a agressividade e a inteligência dos adolescentes que participaram da pesquisa, inicialmente foram realizadas análises estatísticas exploratórias dessas variáveis e verificadas se existiam diferenças significativas entre os sexos. Em seguida foram verificadas as relações entre os diferentes tipos de agressividade e de inteligência avaliados pelos instrumentos da pesquisa, por meio do coeficiente de correlação de Pearson.

Conforme apresentado na Tabela 1 , os índices de agressividade são baixos tanto para a agressividade familiar quanto para a agressividade escolar e geral. Esses resultados são próximos aos encontrados por Sisto (2005), quando foram observadas pontuações médias de agressividade familiar para quatro escolas que participaram do estudo variando de 2,77 (DP=1,97) a 3,26 (DP=2,21), de agressividade escolar variando de 0,76 (DP=1,55) a 1,52 (DP=1,72) e de agressividade geral variando de $3,53(D P=2,77)$ a 4,72 $(D P=3,48)$. Observa-se que quanto à agressividade familiar e a agressividade geral os resultados da presente amostra são semelhantes aos encontrados por Sisto (2005), isto é, estão dentro dos intervalos de valores encontrados pelo pesquisador. Já para a agressividade escolar observa-se que resultados da presente amostra são inferiores aos encontrados pelo pesquisador, indicando, portanto menor agressividade na escola colaboradora deste estudo do que nas quatro escolas pesquisadas por Sisto (2005). 
Segundo Prodocimo e Recco (2008), o comportamento agressivo apresentado na escola é decorrente de uma repetição dos padrões de comportamento das relações familiares, porém não se confirma essa agressividade na dimensão escolar com a presente amostra de adolescentes. $\mathrm{Na}$ dimensão familiar também não apresentam agressividade, no entanto, segundo Gonçalves (2001), os adolescentes geralmente possuem conflitos com a família, pois muitas vezes os pais não compreendem as dificuldades dos filhos e, por esse motivo, também não conseguem impor limites e orientá-los, gerando uma situação de desamparo. Segundo a autora, os pais que durante a infância eram idealizados tornam-se alvo de questionamentos e críticas e assim surgem os conflitos familiares.

Já na pesquisa realizada por Joly e cols. (2009), o escore total de agressividade foi superior ao encontrado na presente pesquisa, mas de forma geral, indicaram poucas condutas agressivas, assim como neste estudo. As autoras também identificaram diferença de agressividade geral entre os sexos dos participantes, apresentando maior nível de agressividade para o sexo masculino do que para o sexo feminino, porém esse resultado não foi observado na presente pesquisa, como apresentado na Tabela 1.

Tabela 1. Estatísticas descritivas e diferenças significativas de agressividade por sexo.

\begin{tabular}{|c|c|c|c|c|c|c|c|c|}
\hline \multirow{2}{*}{ Agressividade } & \multicolumn{2}{|c|}{ Total } & \multicolumn{2}{|c|}{ Feminino } & \multicolumn{2}{|c|}{ Masculino } & \multicolumn{2}{|c|}{$\begin{array}{c}\text { Teste } t \text { de } \\
\text { Student }\end{array}$} \\
\hline & Média & $D P$ & Média & $D P$ & Média & $D P$ & $t(33)$ & $p$ \\
\hline Familiar & 2,97 & 1,79 & 3,04 & 1,86 & 2,71 & 1,60 & 0,420 & 0,677 \\
\hline Escolar & 0,66 & 1,00 & 0,64 & 0,99 & 0,71 & 1,11 & $-0,167$ & 0,868 \\
\hline Geral & 3,63 & 2,25 & 3,68 & 2,62 & 2,42 & 2,37 & 0,259 & 0,797 \\
\hline
\end{tabular}

Também na pesquisa realizada por Guimarães e Pasian (2006) que verificaram a agressividade na adolescência por meio do instrumento STAXI (Inventário de Expressão de Raiva como Traço-Estado) (Spielberger, 1992), foram observadas diferenças significativas entre os sexos na forma de vivenciar e expressar seus sentimentos de raiva. O sexo masculino obteve maior índice de "raiva para fora" (item da escala) em relação ao sexo feminino, indicando que o sexo masculino tende a apresentar maior nível de agressividade em relações de conflitos. 
Em relação ao teste de inteligência houve uma diferença significativa apenas no raciocínio mecânico (Tabela 2). Sendo que os participantes do sexo masculino demonstraram maior habilidade no raciocínio mecânico em comparação ao o sexo feminino. Na pesquisa desenvolvida por Primi e Almeida (2000) para investigar sobre a inteligência de estudantes do Brasil e Portugal, constatou-se um baixo número de acertos dos estudantes brasileiros nas provas de raciocínio da BPR-5, principalmente nas provas de RN (Forma $A$ : $M=4,59$; $\mathrm{DP}=2,60$ e Forma $\mathrm{B}: \mathrm{M}=6,01 ; \mathrm{DP}=3,04)$ ), $\mathrm{RE}$ (Forma $\mathrm{A}: \mathrm{M}=6,01 ; \mathrm{DP}=3,04$ e Forma $B: M=5,76 ; D P=2,93$ ) e $R M$ (Forma $A: M=6,16 ; D P=2,85$ e Forma $B$ : $M=5,76$; $D P=2,68$ ) entre os alunos brasileiros e entre os portugueses para $R N$ (Forma $A: M=6,73$; $D P=3,69$ e Forma $B: M=9,01 ; D P=3,61$ ), RE (Forma $A$ : $M=6,56$; $D P=3,31$ e Forma $B: M=8,82$; $D P=3,70$ ) e RM (Forma $A: M=7,31$; $\mathrm{DP}=2,31$ e Forma $\mathrm{B}: \mathrm{M}=8,77 ; \mathrm{DP}=3,40)$. Já para as outras duas provas os resultados foram melhores, tanto para RA (Forma $A: M=8,53$; $D P=4,14$ e Forma $B: M=8,64$; $D P=3,54$ ), quanto para $R V$ (Forma $A: M=9,64$; $D P=3,58$ e Forma $B$ : $M=10,89 ; D P=3,52$ ) entre os alunos brasileiros e entre os portugueses para $R A$ (Forma $A: M=10,36$; $D P=4,57$ e Forma $B: M=11,39$; $D P=3,18$ ) e para RV (Forma $A: M=11,09 ; D P=4,06$ e Forma $B: M=14,10 ; D P=3,92)$.

Tabela 2. Estatísticas descritivas e diferenças significativas da pontuação média de raciocínio por sexo.

\begin{tabular}{|c|c|c|c|c|c|c|c|c|}
\hline \multirow[t]{2}{*}{ Raciocínio } & \multicolumn{2}{|c|}{ Total } & \multicolumn{2}{|c|}{ Feminino } & \multicolumn{2}{|c|}{ Masculino } & \multicolumn{2}{|c|}{$\begin{array}{c}\text { Teste } t \text { de } \\
\text { Student }\end{array}$} \\
\hline & Média & $D P$ & Média & $D P$ & Média & $D P$ & $t(33)$ & $p$ \\
\hline Abstrato & 13,37 & 4,92 & 13,32 & 4,88 & 13,57 & 5,44 & $-0,119$ & 0,906 \\
\hline Verbal & 11,66 & 4,32 & 11,64 & 4,04 & 11,71 & 5,68 & $-0,039$ & 0,969 \\
\hline Numérico & 6,03 & 3,16 & 6,00 & 2,91 & 6,14 & 4,30 & $-0,105$ & 0,917 \\
\hline Espacial & 8,46 & 4,06 & 8,82 & 3,85 & 7,00 & 4,87 & 1,063 & 0,295 \\
\hline Mecânico & 7,54 & 2,67 & 6,96 & 2,56 & 9,86 & 1,77 & $-2,81$ & $0,008^{*}$ \\
\hline Geral & 47,06 & 14,52 & 46,75 & 13,71 & 48,29 & 18,62 & $-0,247$ & 0,807 \\
\hline
\end{tabular}

Esses mesmos resultados foram observados para a presente amostra, conforme dados apresentados na Tabela 2. Observou-se também que os dados da presente amostra são mais semelhantes aos dados de Portugal do que aos dados do Brasil da pesquisa de Primi e Almeida (2000).

Pela literatura comprova-se que a inteligência e agressividade se relacionam, pois ambas possuem interdependência. Segundo Galvão (1995), 
com base na perspectiva genética de Henri Wallon a inteligência e a afetividade estão integradas. Sendo assim, a evolução da afetividade depende de construções e elaborações realizadas no plano da inteligência, da mesma forma a evolução da inteligência depende de construções afetivas. Wallon ressalta que as emoções são formas de reações organizadas e que são comandadas pelo sistema nervoso central. Sendo assim, as emoções dependem tanto de estímulos externos quanto internos e quando há uma elevação emocional a tendência é ocorrer um baixo desempenho intelectual que ocasiona o impedimento de realizar uma reflexão adequada. No entanto, os resultados desta pesquisa não indicaram relação entre agressividade e inteligência, conforme apresentado na Tabela 3.

Tabela 3. Coeficientes de correlação de Pearson e sua significância estatística entre tipos de agressividade e tipos de raciocínio.

\begin{tabular}{ccccccc}
\hline \multirow{2}{*}{ Agressividade } & $\begin{array}{c}\text { Correlação de } \\
\text { Pearson }\end{array}$ & \multicolumn{5}{c}{ Raciocínio } \\
\cline { 3 - 7 } & & Verbal & Abstrata & Mecânica & Espacial & Numérica \\
\hline \multirow{2}{*}{ Famíliar } & Coeficiente $(r)$ & 0,010 & 0,021 & $-0,138$ & 0,026 & $-0,104$ \\
& Significância $(p)$ & 0,954 & 0,903 & 0,429 & 0,882 & 0,552 \\
\hline \multirow{2}{*}{ Escolar } & Coeficiente $(r)$ & 0,156 &, 033 & 0,116 & 0,163 & 0,152 \\
& Significância $(p)$ & 0,370 & 0,852 & 0,507 & 0,349 & 0,382 \\
\hline \multirow{2}{*}{ Geral } & Coeficiente $(r)$ & 0,077 & 0,031 & $-0,058$ & 0,093 & $-0,015$ \\
& Significância $(p)$ & 0,659 & 0,858 & 0,739 & 0,595 & 0,932 \\
\hline
\end{tabular}

Partindo do pressuposto de que a afetividade desempenha um papel norteador nas decisões e na forma de agir das pessoas perante a sociedade, a agressividade ainda é encarada como algo somente destrutivo, porém é um elemento fundamental para o desenvolvimento do indivíduo, para o estabelecimento do relacionamento interpessoal e sobrevivência.

\section{CONSIDERAÇÕES FINAIS}

O objetivo principal deste estudo foi avaliar, por meio da aplicação da BPR-5 e da Escala de Agressividade para Crianças e Jovens, a relação entre agressividade e inteligência na adolescência. No entanto, foi possível observar que não existe relação entre agressividade e inteligência. Já na literatura pesquisada pode-se constatar que o período da adolescência engloba mudanças 
psicológicas, físicas e sociais, sendo assim, o comportamento do adolescente acaba sendo influenciado por essas alterações, porém o ambiente em que ele está inserido tem grande influência em sua forma de agir.

Para Winnicott (1987), a agressividade sendo demonstrada pelo comportamento antissocial, pode denunciar um histórico de privação emocional, ou seja, pelo fato de não ter tido cuidados essenciais durante o desenvolvimento o indivíduo pode tornar-se agressivo para suportar a falta de cuidados. Segundo Galvão (1995) a teoria de Wallon aponta uma relação de interdependência entre inteligência e afetividade e, sendo assim, os comportamentos são mediados por essas duas variáveis, além do meio ambiente.

Os índices de agressividade encontrados são baixos tanto para a agressividade familiar quanto para a agressividade escolar e geral, no entanto de acordo com a diretora da escola participante deste estudo os alunos são agressivos e apresentam esse tipo de comportamento principalmente no horário do intervalo. A diretora relatou que os professores têm dificuldades para ministrar as aulas em algumas salas por causa da falta de disciplina dos alunos. Além disso, foi informado que os pais dos alunos que possuem maiores queixas não comparecem em reuniões e as famílias possuem condição socioeconômica menos favorecida. A hipótese levantada então é a de que os alunos não responderam ao teste de agressividade com toda sinceridade por conta de desejabilidade social, ou seja, pelo comportamento agressivo ser repreendido em nossa sociedade e, portanto, não seria bom para os alunos que eles mesmos se denunciassem. Isso foi evidenciado pela autora no momento da aplicação dos instrumentos, no qual os alunos hesitavam em responder ao teste de agressividade e, por vezes, perguntavam aos colegas o que tinham respondido para responderem da mesma forma. Assim, sugere-se que outras pesquisas sejam realizadas para ampliar este estudo sobre a influência da agressividade e a inteligência no comportamento dos indivíduos.

\section{REFERÊNCIAS}

Aberastury, A. (1986). Adolescência. Porto Alegre: Artes Médicas.

Almeida, L. S., \& Primi, R. (2004). Perfis de capacidades cognitivas na bateria de provas de raciocínio (BPR-5). Psicologia Escolar e Educacional, 8(2), 135144. 
Almeida, L. S., Lemos, G., Guisande, M. A., \& Primi, R. (2008). Inteligência, escolarização e idade: Normas por idade ou série escolar? Avaliação Psicológica, 7(2), 117-125.

Anastasi, A., \& Urbina, S. (2000). Testagem psicológica. Porto Alegre: Artes Médicas.

Atkinson, R. L., Atkinson. R. C, Smith, E. E., Bem, D. J., \& Nolem-Hoehsema, S. (2002). Introdução à Psicologia de Hilgard. Porto Alegre: Artmed.

Bierman, K. L., Smoot, D. L., \& Aumiller, K. (1993). Characteristics of aggressive-rejected, aggressive (nonrejected), and rejected (nonaggressive) boys. Child Development, 64, 139-151.

Coelho, L. M. S. (1980). Epilepsia e personalidade. (2a ed.). São Paulo: Ática.

Dalgalorrondo, P. (2008). Psicopatologia e semiologia dos transtornos mentais. (2a ed.). Porto Alegre: Artmed.

Dias, E. O. (2000). Winnicott: Agressividade e teoria do amadurecimento. Natureza Humana, 2(1), 9-48.

Erickson, E. (1998). O ciclo de vida completo. Porto Alegre: Artes Médicas.

Freud, S. (1930). O mal-estar na civilização. In: Obras Completas, (vol. XXI). Standard Brasileira. Rio de Janeiro: Imago: (1996).

Galvão, I. (1995). Henry Wallon: uma concepção dialética do desenvolvimento infantil. Rio de Janeiro: Editora Vozes.

Gonçalves, A. C. F. (2001). Conflitos de relacionamento entre pais e filhos: adolescentes no contexto familiar. Trabalho de Conclusão de Curso em Serviço Social, Universidade da Amazônia.

Guimarães, N. M., \& Pasian, S. R. (2006). Agressividade na adolescência: experiência e expressão da raiva. Psicologia em Estudo, 11(1), 89-97.

Hall, C. S., Lindzey, G., \& Campbell, J. B. (2000). Teorias da personalidade. Porto Alegre: Artmed.

Keppe, R. L. D. (2005). Tendência anti-social: A compreensão dos pais sobre a agressividade dos filhos. São Paulo: Centro Universitário Paulistano.

Joly, M. C. R. A., Dias, A. S., \& Marini, J. A. S. (2009). Avaliação da agressividade na família e escola de ensino fundamental. Psico-USF, 14(1) 83-93.

Oliveira, K. S. (2006). Avaliação do exame nacional de desempenho do estudante pela teoria de resposta ao item. Dissertação de Mestrado em Psicologia, Universidade São Francisco, Itatiba. 
Oliveira, D. M. (2009). Contribuições para o estudo da adolescência sob a ótica de winnicott para a educação. Dissertação de Mestrado em Psicologia, Pontifícia Universidade Católica, Campinas.

Papalia, D. E., \& Olds, S. W. (2000). Desenvolvimento humano. (7a ed.). Porto Alegre: Artemed.

Pasquali, L. (2003). Psicometria: teoria dos testes na psicologia e na educação. in Chiodi, M. G. (2007). Escala de inteligência weschesler para crianças e bateria de habilidades cognitivas Woodcok Johson-III: Comparação de instrumentos. Dissertação de Mestrado. Pontifícia Universidade Católica de Campinas.

Primi, R., \& Almeida, L. S. (2000). BPR-5: Bateria de provas de raciocínio: Manual técnico. São Paulo: Casa do Psicólogo.

Pródocimo, E., \& Recco, K. V. (2008). Recreio escolar: Uma análise quantitativa sobre a agressividade entre os estudantes de ensino fundamental I. In: Congresso Nacional de Educação - Educere Educação Internacional. Curitiba: Champagnat, p. 10565-10575.

Sisto, F. F., \& Bazi, G. A. P. (2000). Escala de agressividade para crianças e jovens. Faculdade de Educação. Campinas: Universidade Estadual de Campinas.

Sisto, F. F. (2005). Aceitação-rejeição para estudar a agressividade na escola. Psicologia em Estudo, 10(1), 117-125.

Sisto, F. F., \& Oliveira, A. F. (2007). Traços de personalidade e agressividade: Um estudo de evidência de validade. Revista de Psicologia, 8(1), 89-99.

Spielberger, C. D. (1992). Inventário de Expressão de Raiva como Estado e Traço (S.T.A.X.I): Manual Técnico. Porto Alegre: Vetor.

Sternberg, R. J. (2000). Psicologia Cognitiva. Porto Alegre: Artes Médicas Sul.

Winnicott, D. W. (1975). O brincar e a realidade. Rio de Janeiro: Imago.

Winnicott, D. W. (1987). Privação e delinquência. São Paulo: Martins Fontes.

Winnicott, D. W. (2000). Da pediatria a psicanálise. Rio de Janeiro: Imago.

Contato: julianamunik@yahoo.com.br, cvendramini@uol.com.br

Recebido em: 25/11/2012

Revisado em: 13/12/2012

Aceito em: 27/12/2012 